\title{
OPEN FORIS AND GOOGLE EARTH ENGINE LINKING EXPERT PARTICIPATION WITH NATURAL RESOURCE MAPPING AND REMOTE SENSING TRAINING IN TANZANIA
}

\author{
Ulpu Leinonen ${ }^{a^{*}}$, Joni Koskinen ${ }^{\mathrm{a}}$, Harun Makandi ${ }^{\mathrm{b}}$, Ernest Mauya ${ }^{\mathrm{c}}$, Niina Käyhkö ${ }^{\mathrm{a}}$ \\ a University of Turku (UTU), Department of Geography and Geology, Finland, ulpu.leinonen@utu.fi, +358405631551 \\ ${ }^{\mathrm{b}}$ University of Dar es Salaam (UDSM), Institute of Resource Assessment, Tanzania \\ c Sokoine University of Agriculture (SUA), College of Forestry, Wildlife and Tourism, Department of Forest Operations Management and Techniques, Tanzania
}

Commission IV, WG IV/4

KEY WORDS: Open source, earth observation, remote sensing, geospatial, cloud computing, crowdsourcing, training, Tanzania

\begin{abstract}
:
There is an increasing amount of open Earth observation (EO) data available, offering solutions to map, assess and monitor natural resources and to obtain answers to global and local societal challenges. With the help of free and open source software (FOSS) and open access cloud computing resources, the remote sensing community can take the full advantage of these vast geospatial data repositories. To empower developing societies, support should be given to higher education institutions (HEIs) to train professionals in using the open data, software and tools. In this paper, we describe a participatory mapping methodology, which utilizes open source software Open Foris and QGIS, various open Earth observation data catalogues, and computing capacity of the free Google Earth Engine cloud platform. Using this methodology, we arranged a collaborative data collection event, Mapathon, in Tanzania, followed by a training of the related FOSS tools for HEIs' teaching staff. We collected feedback from the Mapathon participants about their learning experiences and from teachers about the usability of the methodology in remote sensing training in Tanzania. Based on our experiences and the received feedback, using a participatory mapping campaign as a training method can offer effective learning about environmental remote sensing through a real-world example, as well as networking and knowledge sharing possibilities for the participating group.
\end{abstract}

\section{INTRODUCTION}

Space borne remote sensing provides a unique vantage point to monitor the constantly changing Earth and its environmental and human-induced processes holistically. In recent years, high increase of open access to data has been rapidly changing the remote sensing industry. Since NASA, the U.S. Geological Survey, NOAA (Woodcock et al., 2008, Loveland and Dwyer, 2012, Nemani et al., 2011), and lately also the European Space Agency (Copernicus Data Access: Overview, 2016), have started to release medium to high resolution Earth observation data for free, remote sensing has become more accessible an option for mapping projects also in low-income countries. Complementarily, various web platforms and software such as Bing Maps and Google Earth offer very high spatial resolution satellite data for viewing in a readily georeferenced and mosaicked form.

Taking advantage of the full potential of the opened petabytescale geospatial data repositories can be technically overwhelming for a basic laptop or desktop computer user. As an answer to this issue, cloud based computing resources have been developed. Google Earth Engine (GEE, earthengine.google.com) is currently a free option for geospatial cloud computing, with an inbuilt data catalogue giving direct access to many satellite image archives and other geospatial data, as well as high-performance parallel computation service for data processing and analysis (Gorelick et al., 2017). Combined with cloud-based computing resources, the open EO data substantially improve the possibilities to monitor land resource development (Hansen et al., 2013, Dong et al., 2016, Gorelick et al., 2017, Xiong et al., 2017).

* Corresponding author
In addition to cloud-based platforms, there are several free and open source software (FOSS) packages relevant for remote sensing data processing (Steiniger and Hunter, 2013). Including many functionalities and an intuitive graphical user interface, QGIS (qgis.org) is perhaps the most commonly used of these. As another example, the Food and Agriculture Organization of the United Nations (FAO) has developed the Open Foris suite (openforis.org), an open source set of tools enabling the combination of participatory mapping with cloud-based image access and processing. Open Foris Collect Earth software is designed for structured, augmented data collection based on visual interpretation on satellite imagery of Google Earth, among other data providers (Bey et al., 2016). Collect Earth offers a new generation of participatory image interpretation and classification environment, where easy-to-use elements of a public survey are combined with professionally structured visual image interpretation tasks.

While access to open source software and data has improved in remote sensing, new solutions to collect evidence-based information to support image processing have become widely accessible for larger public. These solutions have shifted remote sensing as a professional discipline from restricted expert-based science towards a broader citizen-supportive practice and discourse. Collecting volunteered geographical information (VGI) based on open access repositories of high-resolution satellite images, such as Google Earth, has been lately used for example for validating global and regional scale mapping assessments (Fritz et al., 2009, See et al., 2015a, See et al., 2015b, Estes et al., 2016), land conversion (Jacobson et al., 2015), and forest cover mapping (Schepaschenko et al., 2015, Bastin et al., 2017). These studies have witnessed the potential of crowdsourcing in creating large amount of geographical 
validation data with limited financial resource investment. Such applications are particularly feasible in developing societies where access to national and regional datasets are limited. However, major concern of the VGI campaigns has been the quality control on the collected data (Comber et al., 2013, See et al., 2015b). The quality can be improved by turning these approaches into structured, participatory GIS (PGIS) data collection campaigns, engaging groups of experts with local knowledge, and providing sufficient training prior to the image interpretation.

The benefits of remote sensing are highlighted in vast mapping efforts such as creating national land use and land cover maps required for carbon reporting under the United Nations Framework Convention on Climate Change (UNFCCC). The lack of such regional or country level information especially in rapidly developing countries of the Global South has accelerated the need to train professionals and build the capacity of governments and institutions in remote sensing, and there are several international programs and organizations supporting such activity. However, often the challenge in developing countries is also the limited access to hardware and proprietary software, especially if there is a donor project involved where financial support ends after the conclusion of the project (Haack \& Ryerson, 2016). In addition, the short trainings or workshops may not be sufficient for the participants in the host country or institution to continue the mapping independently afterwards. In a recent review of several major remote sensing journals' issues, Haack \& Ryerson (2016) concluded that very few authors from developing countries were involved in writing the scientific publications. This suggests that careful attention should be paid to how remote sensing related research and competence building is carried out in the developing countries.

The three year project Geospatial and ICT Capacities in Tanzanian Higher Education Institutions (Geo-ICT, geoict.org), a collaboration of Finnish and Tanzanian partners and funded by the Ministry for Foreign Affairs of Finland, has the objective of training the partner universities' teaching staff in order to leave a long-lasting impact. The overall aim of the project is to improve the quality of higher education and research environment in geospatial and ICT fields, and strengthening the role and relevance of these sectors in the development of the society in Tanzania. Tanzanian universities need training with the recently emerged geospatial/ICT technologies and their uses in research and education, and more specifically in adopting these methodologies in their geospatial and remote sensing training. Current research and education environment in many universities lacks critical infrastructures (hardware, software, internet, power supply, materials). Finding solutions for training, where basically only a laptop and internet are needed, data and tools come from the open repositories, and where software and cloud computing can be used, is highly valuable.

In this paper, we discuss the integration of the open data repositories, participatory mapping approaches, and the use of FOSS in remote sensing training in Tanzania. We describe a PGIS mapping campaign, Mapathon, in which we utilized open-access remote sensing data catalogues, open source software, and cloud computing capacity to map forest plantations in the Southern Highlands area of Tanzania. As a part of the Mapathon event, we gathered the learning experiences of the local participants and evaluated the quality of the collected information with the help of ground truth data. The results showcase the unique value of local expert participation, enabling the collection of thousands of reference samples over a large geographical area in a short period of time, and in addition a noteworthy increase in the participants' capacity in using the open access remote sensing tools and visual interpretation of satellite imagery. We also describe how the GeoICT project continues to develop these training experiences and materials from the Mapathon further into remote sensing training contents for Tanzanian universities.

\section{REMOTE SENSING TRAINING USING OPEN SOURCE TOOLS AND PARTICIPATORY MAPPING METHODS}

\subsection{Training visual image interpretation skills and FOSS tools through a participatory mapping task}

In October 2016, we organized a two-week participatory mapping event, Mapathon, at the Geography Department of the University of Dar es Salaam in Tanzania to collect a large reference sample for mapping tree plantations of the Southern Highlands area in southern Tanzania. The Mapathon event was a collaborative effort of the Food and Agriculture Organization of the United Nations (FAO), University of Turku, and the Private Forestry Programme (PFP) operating in southern Tanzania. Twenty-two local participants, including forest officers, university staff and university students were invited from different Tanzanian institutions to take part in the Mapathon.

Prior to the actual data collection, there was a need to train the local participants with the mapping methodology. During the first four days of the event, the participants were given practice with the open source software used for the data collection, Open Foris Collect Earth. Collect Earth allows the online visual interpretation of very high to medium resolution satellite imagery including DigitalGlobe, SPOT, Sentinel-2, Landsat and MODIS, by bridging data repositories of Google Earth, Bing Maps, and Google Earth Engine (Bey et al., 2016). In Collect Earth, the user fills a structured survey form with relevant land cover information for the sample locations based on his/her visual interpretation (Figure 1). This data collection method was selected due to the large (ca. $200,000 \mathrm{~km}^{2}$ ) and partly inaccessible study area to be mapped. A stratified sample of 7,500 points was created for this purpose, each represented by a $30 \times 30 \mathrm{~m}$ plot to be interpreted from the satellite imagery with the help of Collect Earth.

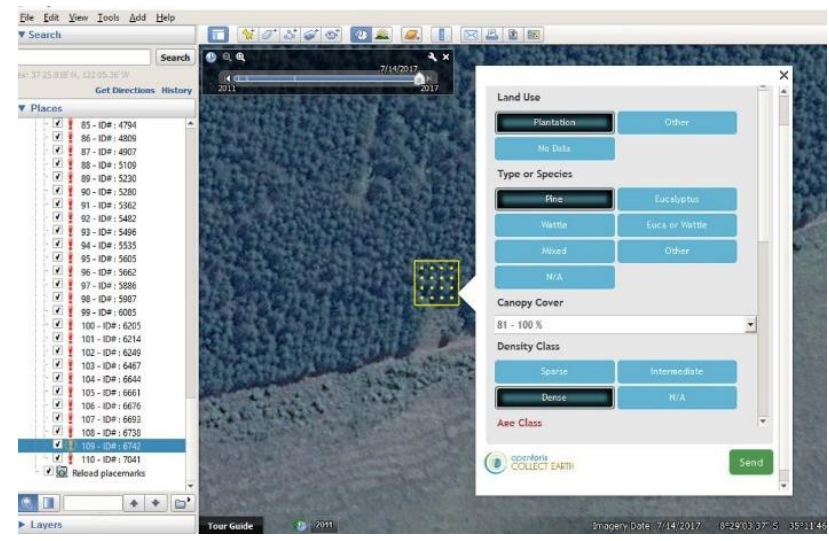

Figure 1. Collect Earth allows filling a structured survey form and facilitates access to Google Earth and other freely available archives of satellite imagery.

The use of Collect Earth was practiced with the help of demonstrations and hands-on exploring of the software and its extensions. The participants used Collect Earth to view plots in both Google Earth and Bing Maps, the parallel use of which is especially beneficial in those cases where only one or the other 
has data available, or more recent imagery existing. Changes in time were studied in Google Earth which offers the historical image viewing option whenever older images exist from a specific site. The participants were also shown how viewing the plot-specific satellite data in Google Earth Engine’s repository is possible through another functionality of Collect Earth. Although having coarser spatial resolution, the temporal and spectral resolution of the data offered by GEE increases the interpretation possibilities substantially. With the scripts Collect Earth generates in GEE Code Editor, the users can even view plotspecific line graphs of inter- and intra-annual vegetation indices derived from satellite imagery. However, using the GEE requires a strong internet connection. Because of the anticipated fluctuations of internet speed, the Mapathon participants were offered a possibility to use previously downloaded auxiliary data from Google Earth Engine and other sources offline in QGIS: the Landsat 8 OLI 2-season mosaics, SRTM digital elevation model (Jarvis et al., 2008) and Worldclim average temperature and mean annual rainfall (Hijmans et al., 2005). The use of multispectral satellite imagery in QGIS, such as selecting band combinations suitable for land cover assessment, was practiced as a part of the training.

In addition to learning how to use the Collect Earth, the group was trained in interpreting the study area land use, land cover (LULC) and forest patterns from the satellite imagery through interactive presentations and by examining satellite images independently as well as in a group. To end up with a consistent result of a PGIS mapping assessment, it is important to synchronize the interpretation process of all participants and agree on the classification system. Thus, the land cover types in the selected classification system were first described by the trainers with the help of photographs from the ground and previously collected information about the basic features and elements in each type. An interpretation guide specific to the study area and its land cover classes used was shared to the group. Thereafter, local participants who knew the study area the best pinpointed locations of these different land covers in the highresolution imagery in Google Earth and presented them to the rest of the group.

As the data collection focused on the separation of planted and natural forests and identification of planted tree species, the forestry and tree plantation experts of the team shared their knowledge about the forest types and planting practices in Tanzania. Examples of forests were viewed together using the high-resolution imagery in Google Earth and Bing Maps, and the medium resolution Landsat imagery from different times of year in Google Earth Engine and QGIS, as the seasonality of the forests was most noticeable in the false-colour band combinations of multispectral images. Based on the discussions had during the interactive training sessions, the land cover classification system was reviewed and some changes were made according to suggestions of the participating team. The locations of known land covers, including the examples of the natural forests and forest plantations, were shared to the whole group for independent studying in both Google Earth and QGIS, and those point data remained for the participants to use as reference information during the mapping task.

\subsection{Collaborative data collection at the Mapathon}

During the second week of the Mapathon, the participants interpreted and recorded the LULC information on individually assigned batches of plots through Collect Earth (Figure 2). Throughout the data collection stage, the interactivity among the group continued and the interpretation challenges were discussed

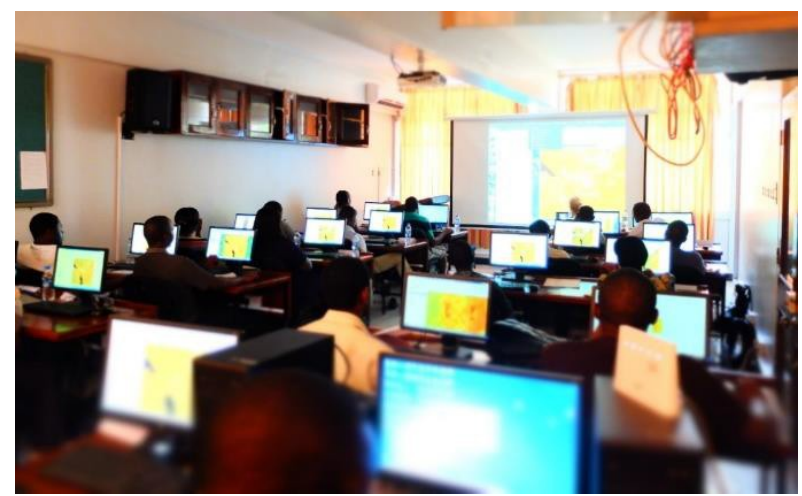

Figure 2. Collaborative data collection at the Mapathon event.

together to accumulate knowledge of all participants and to make shared decisions in problematic situations. The trainers also helped to solve any technical issues with the software and gave more information about the remote sensing related matters when needed. To evaluate the interpretation accuracy of the data collection team, at the end of the training week, 147 known reference locations in the Southern Highlands were interpreted by the local participants and organizer team, and the accuracies were tabulated and compared.

At the end of the data collection, we collected feedback about the learning experiences the Mapathon had offered the participants. We used a feedback form with specified learning statements and open-ended questions. The statements allowed the participants to assess the quality of the event and personal learning experiences on a scale from 1 to 5 , and the open-ended questions gave the participants a chance to describe their key skills after the completion of the Mapathon. We asked which skills the participants felt they specifically learned though the Mapathon, in which remote sensing skills they felt the most confident after the event, and in which skills they felt they would need more practice.

\subsection{Geo-ICT project continuing the training effort}

In the Geo-ICT project, a collaboration of University of Turku, Finland, and four Tanzanian universities, University of Dar es Salaam (UDSM), Ardhi University (ARU), State University of Zanzibar (SUZA), and Sokoine University of Agriculture (SUA) during 2017-2020, one of the aims is to develop the geospatial and ICT related curricula and courses of the partner universities. We have also chosen to promote the use of open source solutions, mobile technologies, crowdsourcing, and PGIS. To achieve these goals, we improve the teaching staff's skills and competence by organizing trainings especially about the recently emerged geospatial/ICT technologies and related pedagogical solutions. The project also takes part in upgrading the Tanzanian partner HEIs' research and education environment with key infrastructures.

In March 2018, at a five-day remote sensing "training for trainers”, i.e. training targeted to junior and senior geospatial and IT teaching staff from the four Tanzanian Geo-ICT project partner universities, twelve participants practiced the use of FOSS in remote sensing. In addition to theoretical background sessions, the training focused on hands-on activity with QGIS, Open Foris, Google Earth and Google Earth Engine. The aim of the training was for the participants to learn the full process of creating and implementing a participatory mapping survey for visual interpretation of high-resolution satellite imagery with the Open Foris software, and then use the data for land cover classification in 
QGIS or Google Earth Engine. In addition, we practiced the creation of the sample locations in QGIS and building the user-defined survey questions and attributes in Open Foris Collect.

At the end of the training, the group discussed the possibilities to integrate the used tools and Mapathon-like events in the Tanzanian universities' geospatial and remote sensing courses. The potential courses, possible challenges, and needed follow-up actions were listed by the university teams (Figure 3). Each participant also gave general feedback about the training and software. The Geo-ICT project continues its activities based on the feedback, for example by offering intensive 3-month training for two experts from each partner university during 2018. The experts can then, with the support of the curricula development teams at each university, work on the modification of the geospatial and remote sensing course contents and materials based on each university's needs.

\section{RESULTS}

\subsection{Quality of training samples from the participatory mapping campaign}

During the 5 days of data collection at the Mapathon, the participants collected 6,871 land cover and forest plantation samples. These samples were used as reference data to classify multi-sensor image stack into a forest plantation map in GEE. The interpretation accuracy varied among the participants. For the participants with previous knowledge on remote sensing and image interpretation, the interpretation accuracy was higher than for those with no prior experience on image interpretation. Nevertheless, the average participants' agreement on the interpreted plantation reference points was over $80 \%$. This agreement is high, especially considering that the plantations are challenging to interpret visually from satellite imagery due to the variance within the patch size, species, age and conditions.

The agreements were lower but still relatively high for differentiating the plantation species. Pine plantations were identified with over $70 \%$ agreement while eucalyptus and wattle plantations were identified with 55\% agreement. This result was also expected, since during the data collection the participants had significantly more challenges in defining eucalyptus, wattle and natural forest cover compared to defining pine cover. Considering the other land covers than plantations (e.g. woodland or bushland) the agreements were $50 \%$ or less. These lower values can be explained by the content of training where the semantics and the physical features of plantations were on the focus. Altogether, the interpretation agreements highlight the importance of the training in calibrating the individual interpretations.

\subsection{Participatory mapping campaign as a learning experience}

Based on the feedback collected from the Mapathon participants, all felt that they had substantially benefited from the experience. The used software were all new to most of the participants since only two experts had previous experience with Open Foris tools. However, most of them had been using Google Earth in their studies or professional work. The participants had most differences in their local field knowledge. The average familiarity with the site was 4.1/5.0, with few participants who had never visited the region. Also, there was less confidence with field based remote sensing methods among the participants (avg. score 3.9/5.0).

All participants stated that the experience was positive in general and that they were highly motivated to take part (avg. score
4.9/5.0). Although the process included challenging interpretation tasks, the participants felt that their understanding of the exercise was high (avg. score 4.3/5.0). They stated that their skills in remote sensing and image interpretation after the Mapathon were much better than before and their understanding on the applications more concrete (avg. score 4,7/5.0). Most of the participants said that their knowledge in environmental remote sensing, especially visual image interpretation had increased. Most of them also appreciated learning how to use new software and tools in remote sensing and GIS. Many were able to list in detail, which type of skills they learned, and what kind of further support they would need to enhance their competence in environmental remote sensing.

The orientation week was considered necessary in providing the participants with required skills for interpretation task and to share knowledge to modify the survey. Based on the feedback, the participants were keen to deepen their expertise on the image interpretation and analysis in the GEE platform. The participants were also interested in learning how to design a Collect Earth survey with the Open Foris Collect tool. Such training was held as part of the results dissemination event arranged for the participants after the mapping work had been finalized.

\subsection{Possibilities of FOSS and participatory methods integration in Tanzanian universities' remote sensing training}

Based on the feedback collected at the Geo-ICT project's remote sensing training for trainers, all universities' representatives were eager to adopt some of the training contents into their courses. In general, the transition from commercial GIS and remote sensing software to FOSS options was seen highly welcome, new means to utilize the freely open data sets were called for, and the use of cloud environments such as GEE interested many. The lack of technical or programming skills needed in some of the presented tools was considered a hindrance to their integration in the universities' courses, and many mentioned this would be an important topic for follow-up training. One identified solution to overcome the technical difficulties was the collaboration of those departments that traditionally teach GIS and remote sensing (e.g. Geography and Geoinformatics) with the ICT departments in course development. This might be beneficial especially with the introduction of those tools that require some programming skills, such as the GEE Code Editor.

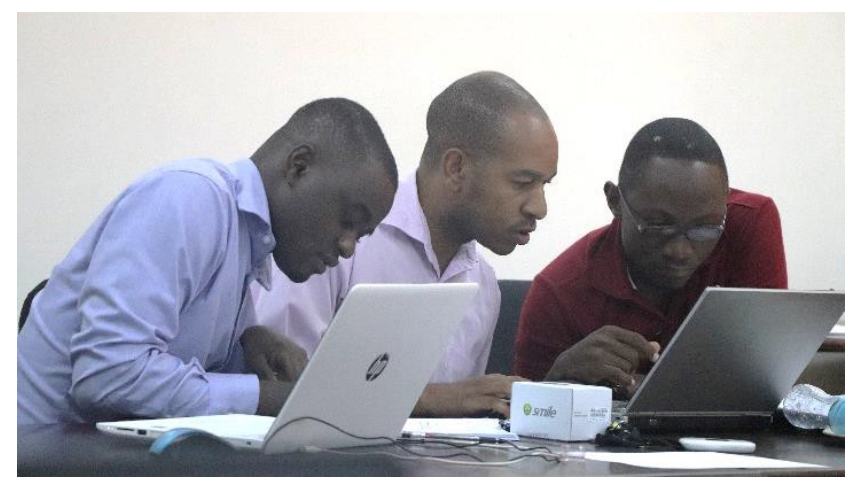

Figure 3. The participants of each university teamed up to discuss and plan the use of FOSS in their remote sensing courses.

There was general interest in teaching the collective use of FOSS tools through a participatory mapping task such as the Mapathon. However, nearly all the trainers named lack of stable and fast internet connection as the main barrier when it comes to integrating all parts of the methodology in their remote sensing 
teaching. The adoption of tools that require a lot from the internet speed should thus perhaps have offline or less internetdemanding options available. On the other hand, the trainers thought the remote sensing related features in QGIS software and the easy-to-use Collect Earth software could rather straightforwardly be embedded in their training contents.

\section{DISCUSSION}

Remote sensing allows developing countries affordable collection of information for planning, policy development and decision-making purposes, which can benefit the countries' economies as well as their self-reliance, self-sufficiency and selfsustainment (Adedeji, 1988). In developing societies, there is a high need to shift to open source software and have better means to utilize the free Earth observation data. This progress requires capacity building of the remote sensing community, which can be implemented in various ways. Short-term advanced training is an efficient approach to technology transfer and commonly used for example by the United Nations and other international agencies. However, extended trainings with follow-up procedures can lead to results that are more permanent. Both methods work the best when the selected participants have the required mandate and resources to implement the concepts of the training in their home organization, the training contains enough hands-on activities and is done with software and hardware which remains accessible to the participants also after the training (Haack \& Ryerson, 2016). Thus, building the training methodologies on FOSS is crucial to ensure the participants have the ability to continue to develop their own skills and introduce the new tools at their home organization. For instance, in the field of land resource mapping, Open Foris suite combined with open satellite image repositories and cloud computing resources of GEE, facilitates a powerful set up for environmental remote sensing applications (Bastin et al., 2017, Gorelick et al., 2017).

Our results show that gathering participants for an intensive data collection campaign can be an effective way to teach the use of new remote sensing tools, as it enables learning through handson activity and a real-world example. A participatory data collection event is a collaborative learning environment allowing knowledge sharing, while simultaneously incorporating better control over the reliability of the collected information through calibration of the semantics and structured feature recognition. Based on our experience, knowledge sharing is an important part of such events: the participants do not only learn from the trainer but also from each other, as experts of different fields can offer practical knowledge for the benefit of the whole group. The training period allows also the trainers to learn from the participants and use that knowledge to modify the task with respect to the skills and interpretation capacity of the participants. Participants can also take advantage of the networking potential of such events, and the common task builds team-working skills. Such key elements motivate the participants, ensure the success of mapping task and additionally empower the developing societies facilitating better access and opportunities for natural resource mapping and management through capacity building and in creating expert networks (McCall et al., 2015, Verplanke et al., 2016).

Although international support for the training of remote sensing professionals in organisations of developing countries is welcome, involving the local higher education institutions makes the capacity development more sustainable. If the local HEIs are supported in adopting FOSS in their geospatial and remote sensing curricula, they can produce skilled professionals in a more consistent manner, empowering the developing societies also in the long run. As the aims of the three-year Geo-ICT project are to train the teaching staff and develop the partner universities' geospatial and IT curricula, it also offers a great opportunity to capacitate those people who are able to institutionalize the new methodologies by embedding FOSS tools into the undergraduate and postgraduate degree training at Tanzanian universities. We plan to continue by developing the training materials for remote sensing courses of the universities and further training of the key persons in each university.

\section{CONCLUSIONS}

In this paper, we demonstrated a methodology to link local expertize in natural resource remote sensing through a PGIS mapping campaign. Built on FOSS combined with open image repositories, and supplemented with freely accessible cloud computing platform, such methodological set up is promising for natural resource mapping especially in data scarce and rapidly developing countries in the Global South. To ensure the empowerment effect and motivational nature of such mapping campaigns, the methodological flow needs to not only be based on FOSS and open datasets but also include clear benefits for the voluntary participants of the mapping, such as knowledge sharing and networking possibilities and qualifications resulting from the learning experience. Furthermore, when the methodology is institutionalized by integrating it in the curricula of local HEIs it will become formalized, replicable, and adaptable according to the most recent data, technologies and tools. This will ensure the continuity, commitment, and ownership of the process and lead to increased societal capacity to conduct natural resource mapping.

\section{ACKNOWLEDGEMENTS}

We thank the FAO and Academy of Finland (project: Sustainability, scale relations and structure-function-benefit chains in the landscape systems of the Tanzanian Southern highlands (SUSLAND), 276126) for supporting the participatory mapping campaign. We also thank Ministry of Foreign Affairs of Finland for funding the on-going The GEO-ICT project (2017-2020) and the whole GEO-ICT project team for commitment and enthusiasm towards development of geospatial and ICT capacities in Tanzania and in Finland. Special thanks to all participants of the Mapathon event and Geo-ICT training and to University of Dar es Salaam Department of Geography for facilitating the Mapathon event.

\section{REFERENCES}

Adedeji, A., 1988. Remote sensing and African development programmes. Photogrammetria, 43 (1), 17-24.

Bastin, J., Berrahmouni, N., Grainger, A., Maniatis, D., Mollicone, D., Moore, R., Chiara, P., Picard, N., Sparrow, B., Abraham, E.M., Aloui, K., Atesoglu, A., Attore, F., Bassullu, C., Bey, A., GArzuglia, M., Garcia-Montero, L.G., Groot, N., Guerin, G., Laestadius, L., Lowe, A.J., Mamane, B., Marchi, G., Pattersson, P., Rezende, M., Ricci, S., Salcedo, I., Sanchez-Paus Diaz, A., Stolle, F., Surappaeva, V., and Castro, R., 2017. The extent of forest in dryland biomes. Science, 356, 635-638

Bey, A., Diaz, A.S., Maniatis, D., Marchi, G., Mollicone, D., Ricci, S., Bastin, J., Moore, R., Federici, S., Rezende, M., Patriarca, C., Turia, R., Gamoga, G., Abe, H., Kaidong, E., and Miceli, G., 2016. Collect Earth: Land Use and Land Cover 
Assessment through Augmented Visual Interpretation. Remote Sensing, 8, 807.

Comber, A., See, L., Fritz, S., Van der Velde, M., Perger, C., and Foody, G., 2013. Using control data to determine the reliability of volunteered geographic information about land cover. International Journal of Applied Earth Observation and Geoinformation, 23, 37-48.

Copernicus Data Access: Overview, 2016 http://www.copernicus.eu/sites/default/files/Data_Access/Data_ Access_PDF/Factsheet_Data_Access_Overview.pdf (May $16^{\text {th }}$, 2018).

Dong, J., Xiao, X., Menarguez, M.A., Zhang, G., Qin, Y., Thau, D., Biradar, C., and Moore, R. 2016. Mapping paddy rice planting area in northeastern Asia with Landsat 8 images, phenology-based algorithm and Google Earth Engine. Remote Sensing of Environment, 185, 142-154.

Estes, L.D., McRitchie, D., Choi, J., Debats, S., Evans, T., Guthe, W., Luo, D., Ragazzo, G., Zempleni, R., and Caylor, K.K., 2016. A platform for crowdsourcing the creation of representative, accurate landcover maps. Environmental Modelling and Software, 80, 41-53.

Fritz, S., McCallum, I., Schill, C., Perger, C., Grillmayer, R., Achard, F., Kraxner, F., and Obersteiner, M., 2009. GeoWiki.Org: The Use of Crowdsourcing to Improve Global Land Cover. Remote Sensing, 1, 345-354.

Gorelick, N., Hancher, M., Dixon, M., Ilyushchenko, S., Thau, D., and Moore, R., 2017. Google Earth Engine: Planetary-scale geospatial analysis for everyone. Remote Sensing of Environment, 202, 18-27.

Haack, B. and Ryerson, R., 2016. Improving remote sensing research and education in developing countries: Approaches and recommendations. International Journal of Applied Earth Observation and Geoinformation, 45, 77-83.

Hansen, M.C., Potapov, P.V., Moore, R., Hancher, M., Turubanova, S.A., Tyukavina, A., Thau, D., Stehman, S.V., Goetz, S.J., Loveland, T.R., Kommareddy, A., Egorov, A., Chini, L., Justice, C.O. and Townshend, J.R.G., 2013. High-Resolution Global Maps of 21st-Century Forest Cover Change. Science, 342, 850-853.

Hijmans, R., Cameron, S., Parra, J., Jones, P. and Jarvis, A., 2005. Very high resolution interpolated climate surfaces for global land areas. International Journal of Climatology, 25, 1965-1978.

Jacobson, A., Dhanota, J., Godfrey, J., Jacobson, H., Rossman, Z., Stanish, A., Walker, H. and Riggio, J., 2015. A novel approach to mapping land conversion using Google Earth with an application to East Africa. Environmental Modelling and Software, 72, 1-9.

Jarvis, A., Reuter, H.I., Nelson, A. and Guevara, E., 2008. Holefilled SRTM for the globe Version 4.

Loveland, T.R., Dwyer, J.L., 2012). Landsat: Building a strong future. Remote Sensing of Environment, 122, 22-29.

McCall, M., Martinez, J. and Verplanke, J., 2015. Shifting Boundaries of Volunteered Geographic Information Systems and
Modalites. ACME: An International E-Journal for Critical Geographies, 14(3), 791-826.

Nemani, R., Votava, P., Michaelis, A., Melton, F., Milesi, C., 2011. Collaborative supercomputing for global change science. EOS Trans. American Geophysical Union, 92 (13), 109-110.

Schepaschenko, D., See, L., Lesiv, M., McCallum, I., Fritz, S., Salk, C., Moltchanova, E., Perger, C., Shchepashchenko, M., Shvidenko, A., Kovalevskyi, S., Gilitukha, D., Albrecht, F., Kraxner, F., Bun, A., Maksyutov, S., Sokolov, A., Duerauer, M., Obersteiner, M., Karminov, V. and Ontikov, P., 2015. Development of a global hybrid forest mask through the synergy of remote sensing, crowdsourcing and FAO statistics. Remote Sensing of Environment, 162, 208-220.

See, L., Schepaschenko, D., Lesiv, M., McCallum, I., Fritz, S. Comber, A., Perger, C., Schill, C., Zhao, Y., Maus, V., Siraj, M.A., Albrecht, F., Cipriani, A., Vakolyuk, M., Garcia, A., Rabia, A.H., Singha, K., Marcarini, A.A., Kattenborn, T., Hazarika, R., Schepaschenko, M., van der Velde, M., Kraxner, F. and Obersteiner, M., 2015a. Building a hybrid land cover map with crowdsourcing and geographically weighted regression. ISPRS Journal of Photogrammetry and Remote Sensing, 103, 48-56.

See, L., Fritz, S., Perger, C., Schill, C., McCallum, I., Schepaschenko, D., Duerauer, M., Sturn, T., Kamer, M., Kraxner, F. and Obersteiner, M., 2015b. Harnessing the power of volunteers, the internet and Google Earth to collect and validate global spatial information using Geo-Wiki. Technological Forecasting and Social Change, 98, 324-335.

Steiniger, S.S. and Hunter, A.J.S., 2013. The 2012 free and open source GIS software map - a guide to facilitate research, development, and adoption. Computers, Environment and Urban Systems, 39, 136-150.

Verplanke, J., McCall, M.K., Uberhuaga, C., Rambaldi, G. and Haklay, M., 2016. A Shared Perspective for PGIS and VGI. Cartographic Journal, 53, 308-317.

Woodcock, C.E., Allen, A.A., Anderson, M., Belward, A.S., Bindschadler, R., Cohen, W.B., et al., 2008. Free access to Landsat imagery. Science, 320, 1011.

Xiong, J., Thenkabail, P.S., Gumma, M.K., Teluguntla, P., Poehnelt, J., Congalton, R.G., Yadav, K. and Thau, D., 2017. Automated cropland mapping of continental Africa using Google Earth Engine cloud computing. ISPRS Journal of Photogrammetry and Remote Sensing, 126, 225-244. 